\title{
Correlation of swelling and sorption properties of block coal sample
}

\author{
Fengshuang Han ${ }^{\mathrm{a}, \mathrm{b}}$, Guoqing Chen ${ }^{\mathrm{c}, \mathrm{d}, \mathrm{b}}$, Zhenyu Liu ${ }^{\mathrm{e}}$, Jianli Yang ${ }^{\mathrm{f}, \mathrm{b} *}$ \\ ${ }^{a}$ Ningbo University of Technology, Ningbo 315211, P.R. China \\ ${ }^{b}$ Institute of Coal Chemistry, Chinese Academy of Sciences, Taiyuan 030001, China \\ ${ }^{c}$ Shanxi Province Guoxin Energy Development Group CO., LTD, Taiyuan 030006, \\ P.R. China \\ ${ }^{d}$ Shanxi Research and Design Institute of Low Carbon Utilization of High Carbon \\ Energy, Taiyuan 030006, P.R. China \\ ${ }^{e}$ State Key Laboratory of Chemical Resource Engineering, Beijing University of \\ Chemical Technology, Beijing 100029. P.R. China \\ ${ }^{f}$ National Energy Center for Coal to Liquids, Synfuels CHINA Co., Ltd, \\ Beijing, 101407, P.R. China \\ *Corresponding author: Tel./fax: +86010 64421073.Email: liuzy@mail.buct.edu.cn \\ (Z. Liu); Tel./fax: +86 010 69667133. Email: jyang@sxicc.ac.cn (J. Yang)
}

\section{ABSTRACT}

The swelling and sorption experiments were carried out simultaneously for two block coal samples under $\mathrm{CO}_{2}$ and $\mathrm{CH}_{4}$ pressure (up to $16 \mathrm{MPa}$ ) at three temperatures $\left(25,45\right.$ and $\left.65^{\circ} \mathrm{C}\right)$. The absolute sorption isotherms present type- $I I$ pattern and can be described by a modified BET model. The swelling isotherms present $L$-type pattern and can be described by a modified Langmuir model. The relationship between swelling ratio and absolute sorption amount presents $S$-type pattern and can be described by a modified Gompertz function (a logistic function). It is interesting to find that the correlations of normalized properties have a single relationship that is independent of experimental conditions, coals and gases. When the sorption amount approaches to the monolayer sorption coverage $\left(n_{d} / n_{m}=1\right)$, the swelling ratio reaches $\sim 93 \%$ of the maximum swelling ratio. It implies the importance of the mutual contact between coal and sorbate. The differential characteristic of swelling process shows that the swelling rate with respect to sorption amount varies with the sorbate coverage; the swelling rate peaks at $\mathrm{n}_{\mathrm{a}} / n_{m} \approx 0.37$ and approches zero at $\mathrm{n}_{\mathrm{a}} / n_{m} \approx 1.5$. In addition, a theoretical model correlating swelling and sorption was established. The concept of reduction of surface free energy by sorption was taken into account. It is encouraged that the experiment data match of model is generally acceptable.

Keywords: CBM; Block coal sample; Absolute sorption; Swelling isotherm 


\section{Nomenclature}

$2 a$ : thermodynamic constant in modified BET sorption model in Eq. 11

3 A: constant in the relationship between swelling ratio and change of surface free energy in Eq. 14

$5 \quad b$ : constant in van der Waals equation of state

$6 \quad c[\mathrm{~mol} / \mathrm{l}]$ : concentration of sorbate in bulk phase

$7 \quad c_{a}[\mathrm{~mol} / \mathrm{l}]$ : concentration of sorbate in sorbed phase

$8 e$ [1/mol]: constant in the mathematical correlation of compressibility factor with concentration of sorbate in bulk phase $E[\mathrm{~Pa}]$ : Young's modulus of coal $h$ : constant in modified Langmuir model in Eq. 12 $L_{0}[\mathrm{dm}]$ : height of block coal at atmospheric pressure $L[\mathrm{dm}]$ : height of block coal at a given pressure and temperature $m$ : constant in the modified Gompertz function in Eq. 13 $m_{\text {coal }}[\mathrm{kg}]$ : mass of coal sample $n_{e}[\mathrm{~mol} / \mathrm{kg}$-coal]: excess sorption amount per kilogram of coal $n_{m}$ [mol/kg-coal]: absolute sorption amount required to form a monolayer $n_{\text {total }}[\mathrm{mol}]:$ total amount of sorbate feed into sample cell $P[\mathrm{~Pa}]:$ equilibrium pressure of bulk phase in sample cell $\mathrm{r}[\mathrm{m}]$ : initial nominal radius of block coal sample at atmospheric pressure. $R[\mathrm{~J} /(\mathrm{mol} \cdot \mathrm{k})]$ : universal gas constant $S\left[\mathrm{~m}^{2} / \mathrm{m}^{3}\right]$ : specific surface area of coal sample $T[\mathrm{~K}]:$ tested temperature $V_{a}$ [1]: volume of sorbate in sorbed phase $V_{0}$ [1]: initial volume of block coal sample at atmospheric pressure $V_{\text {void }}$ [1]: total void volume of sample cell at the quasi-equilibrium state $V_{\text {void,initial }}[1]$ : void volume of sample cell before sorption occurs $x_{c}$ : constant in modified Gompertz function in Eq. 13 $z$ : compressibility factor of sorbate $\Delta V[1]$ : volume increase of coal sample due to coal swelling $\varepsilon$ : swelling ratio of block coal sample $\varepsilon_{m}$ : maximum swelling ratio of coal sample at the specified temperature $\varepsilon_{m-L}:$ maximum swelling ratio of coal sample predicted by modified Langmuir model 
$3 \Phi\left[\mathrm{J} /\left(\mathrm{kg} \cdot \mathrm{m}^{2} / \mathrm{m}^{3}\right)\right]$ : change of the Gibbs free energy of coal induced by sorption

$4 \rho\left[\mathrm{kg} / \mathrm{m}^{3}\right]$ : density of coal sample

\section{Introduction}

Coalbed methane (CBM), a form of natural gas trapped within coal seam by sorption, has become an important source of energy. To overcome the low production rate of $\mathrm{CBM}$, a process known as $\mathrm{CO}_{2}$-ECBM is developed. Injecting $\mathrm{CO}_{2}$ into coal seams is expected to enhance CBM recovery, mainly by the competitive sorption of $\mathrm{CO}_{2}$ over CBM. In addition, storage of $\mathrm{CO}_{2}$ in unminable coal seams may be an option for mitigating climate change.

However, most of the pilot tests of $\mathrm{CO}_{2}$-ECBM worldwide encountered a reduction in injection rate of $\mathrm{CO}_{2}$ with time, which is generally considered to be caused by $\mathrm{CO}_{2}$ sorption-induced-swelling of coal [1-5]. The "swelling" of coal refers to an increase in its volume, which can result in a reduction in the porosity of coalbed confined by surrounding rocks. It, in turn, can induce a dramatic decrease of permeability of coal seam. Accurate estimation of the swelling extent and understanding the swelling mechanism of coal has important significance on the prediction of the dynamic change of CBM production.

Coal is plant fossil and consists primarily of organic material admixed with smaller quantities of mineral matter. The physical structure of organic components represents the spatial arrangement of cross-linked macromolecular networks of coal. Coal behaves like porous materials, having either plastic or elastic properties. It can swell by imbibing appropriate solvents or gases under appropriate conditions. The swelling of coal by organic solvents are widely studied and well understood, while swelling process of coal under gas pressure is not well understood.

Besides $\mathrm{CO}_{2}$, some of other gases can induce swelling of coal as well, but to varying degrees. Considering the degree of swelling, $\mathrm{CO}_{2}$ is more effective than $\mathrm{CH}_{4}$ [3, 6-8]. It has been reported that the degree of swelling decreases in the order of $\mathrm{CO}_{2}>\mathrm{Xe}>\mathrm{C}_{2} \mathrm{H}_{6}>\mathrm{Kr}>\mathrm{CH}_{4}>\mathrm{CF}_{4}>\mathrm{Ar}>\mathrm{N}_{2}$; and the swelling induced by Helium and Neon is negligible [5]. This order is consistent with the order of sorption capacity of coal for the corresponding gases. The degree of swelling was also tried to correlate with the critical temperature of gas. The out of order points were observed although the main trend seems consistent. 
Furthermore, the out of order points were also observed for the relationship between the degree of swelling and gas type although the rule of like dissolves like was basically followed. In comparison with the solubility parameter of other gases, the solubility parameter of $\mathrm{CO}_{2}\left(15 \mathrm{MPa}^{0.5}\right)$ is closer to the solubility parameter of coal $\left(\sim 25 \mathrm{MPa}^{0.5}\right)$, which is agreed with the higher imbibition of $\mathrm{CO}_{2}$ in coal structure and the higher degree of swelling induced. In comparison with the solubility parameter of $\mathrm{CH}_{4}\left(12 \mathrm{MPa}^{0.5}\right)$, the solubility parameter of $\mathrm{Ar}\left(14 \mathrm{MPa}^{0.5}\right)$ is closer to the solubility parameter of coal $\left(\sim 25 \mathrm{MPa}^{0.5}\right)$. However, it is common knowledge that the sorption ability of Ar on coal and the swelling induced are significantly less than those with respect to $\mathrm{CH}_{4}$. It indicates that the characteristics of sorption and swelling of coal are not simply controlled by a single property of sorbate.

Besides gas type, the degree of swelling is also affected by other factors, such as temperature, gas pressure and coal type. Nevertheless, it has been noticed that the correlation patterns with respect to above factors for swelling and sorption are similar $[2,6]$. Therefore, the swelling of coal under gas pressure is somehow associated with the sorption of coal [9-11].

Although the swelling and sorption of coal are known being somewhat related, it is difficult to correlate two properties properly and quantitatively. The excess sorption amount, rather than the absolute sorption amount, is usually used in the correlation, because the volume of sorbed phase and the volume change of coal by swelling are hard to be estimated.

An approximate linear relationship between the swelling and sorption was observed under low and moderate pressure and was used in the historical matching of ECBM process [12]. A quadratic polynomial expression was developed by fitting the swelling and sorption data from three coal samples and eight gases [5]. It can be found that both expressions are not suitable for high sorption capacity or high pressure conditions. In practice, the Langmuir type swelling isotherm is observed. It means that as the pressure increases the swelling ratio should be leveled out rather than increases continuously as predicted by both expressions.

In order to obtain the proper relationship between sorption and swelling properties of coal, the swelling and sorption behaviors of two block coal samples under $\mathrm{CO}_{2}$ and $\mathrm{CH}_{4}$ pressure (up to $16 \mathrm{MPa}$ ) was investigated experimentally and theoretically in this study. The swelling ratio and excess sorption amount of block coal sample were measured simultaneously. The absolute sorption amount was calculated 
and correlated with the corresponding swelling ratio. An attempt was made to establish a mathematic relationship of swelling and sorption, by which the swelling behavior of coal may be predicted from the sorption isotherm or vice versa, and to further understand the mechanism involved.

\section{Simultaneous measurement of swelling and sorption of block coal} sample

\subsection{Test sample}

Two high rank coals, Yangquan (YQ) and Qinshui (QS), from Shanxi province of China were invesigated. Table 1 summarizes the proprties of coals. The rank of QS coal is slightly higher than that of YQ coal.

A chunk coal was made into several cylindrical blocks for the measurement. The size of block coal sample is about $17 \mathrm{~mm}$ in diameter and about $70 \mathrm{~mm}$ in height. The axial of coal samples is parallel to the bedding plan of coal seam.

\subsection{Swelling and sorption measurement and data processing}

\subsubsection{Swelling and sorption measurement}

An apparatus for the sorption measurement was modified to measure the sorption and swelling simultaneously. Similar to the conventional manometric gas sorption apparatus, it consists of two stainless-steel cells (as reference and sample cells), two high-precision pressure transducers, and a set of valves, as shown in Fig. 1 [13]. A high sensitivity linear variable differential transformer (LVDT) displacement transducer is assembled on top of the sample cell to monitor the axial deformation of coal sample. The maximum measuring scale of the LVDT displacement transducer is $2 \mathrm{~mm}$ with a precision of $0.1 \%$ in terms of the full-scale value. The setup can be operated under extreme conditions, including the sub- and supercritical $\mathrm{CO}_{2}$ situations. A thermostat was used to ensure the constant temperature during the mensurement.

The measurements were started by determining the volume of the reference cell and the initial void volume of the sample cell with coal sample according to helium expansion technique. Then the reference cell was filled with the designated gas/supercritical fluid and expanded into the sample cell. The axial deformation of the coal sample was measured for convenience and recored by a displacement transducer. The pressure changes in reference and sample cells were recorded by two pressure transducers.

\subsubsection{Swelling parameter}


2 which is the relative change ratio of axial length of block coal sample.

$3 \quad \varepsilon=\frac{L-L_{0}}{L_{0}}$

4 where $L_{0}$ is the initial axial length of block coal sample at atmospheric pressure, in $5 d m ; L$ the axial length of block coal sample at a measure pressure and temperature, in $6 d m$.

$28 \quad n_{\mathrm{a}}=\mathrm{n}_{e}+\frac{c\left(\mathrm{~V}_{\mathrm{a}}+\Delta \mathrm{V}\right)}{\mathrm{m}_{\text {coal }}}$

\subsubsection{Sorption parameter}

The absolute sorption amount per kilogram of coal $\left(n_{a}\right)$ at the quasi-equilibrium state can be calculated by subtracting the amount of fluid molecules that should present in the void volume in bulk phase in the absence of adsorption from the total fluid feed into the sample cell:

$n_{\mathrm{a}}=\frac{\mathrm{n}_{\text {total }}-\mathrm{c} \cdot V_{\text {void }}}{\mathrm{m}_{\text {coal }}}$

where $c$ denotes the concentration of sorbate in bulk phase of sample cell, in $\mathrm{mol} / \mathrm{l}$; $m_{\text {coal }}$ the mass of coal sample, in $\mathrm{kg} ; n_{\text {total }}$ the total amount of sorbate feed into sample cell, in mol and $V_{\text {void }}$ the total void volume of sample cell at the quasi-equilibrium state, in $l$.

In practice, the $n_{a}$ is difficult to be obtained directly because the $V_{\text {void }}$ in Eq. 2 is not constant. The $V_{\text {void }}$ varies with the volume change of sorbed phase, $V_{a}$, and the volume change of coal sample, $\Delta V$, corresponding to swelling or shrankage, as the following:

$V_{\text {void }}=V_{\text {void,initial }}-V_{a}-\Delta V$

where $V_{\text {void,initial }}$ is the void volume of sample cell before sorption occurs, in $l$. Take Eq. 3 into account, the Eq. 2 becomes:

$n_{\mathrm{a}}=\frac{\mathrm{n}_{\text {total }}-\mathrm{c} \cdot\left(V_{\text {void,initial }}-V_{a}-\Delta V\right)}{\mathrm{m}_{\text {coal }}}$

The excess sorption amount $\left(n_{e}\right)$ is easy to be obtained and is defined as:

$$
n_{e}=\frac{\mathrm{n}_{\text {total }}-\mathrm{c} \cdot V_{\text {void,initial }}}{\mathrm{m}_{\text {coal }}}
$$

The volume of sorbed phase $V_{a}$ in Eq. 6 can be estimated by the following equation: 
$1 \quad V_{a}=\frac{\mathrm{n}_{a} m_{\text {coal }}}{c_{a}}$

where $c_{a}$ is the concentration of sorbed phase, in mol/l.

Assuming that the geometry of coal varies isotropically as shown in Eq. 8

$$
\varepsilon=\frac{\mathrm{L}-\mathrm{L}_{0}}{\mathrm{~L}_{0}}=\frac{\mathrm{r}-\mathrm{r}_{0}}{\mathrm{r}_{0}}
$$

The volume change of coal sample, $\Delta V$, can be estimated as follows:

$$
\begin{array}{r}
\Delta V=V-V_{0}=\pi \mathrm{r}^{2} L-\pi \mathrm{r}_{0}^{2} L_{0}=\pi\left(\mathrm{r}_{0}+r_{0} \varepsilon\right)^{2}\left(L_{0}+L_{0} \varepsilon\right)-\pi \mathrm{r}_{0}^{2} L_{0} \\
=\pi \mathrm{r}_{0}^{2} L_{0}\left[(1+\varepsilon)^{3}-1\right] \approx 3 \pi \mathrm{r}_{0}^{2} L_{0} \varepsilon=3 V_{0} \varepsilon
\end{array}
$$

where $r_{0}$ is the initial radius of block coal sample at atmospheric pressure, in $d m ; r$ the radius of block coal sample at a measure pressure and temperature, in $d m ; V_{0}$ the initial volume of block coal sample at atmospheric pressure, in $l$; and $V$ the volume of block coal sample at a measure pressure and temperature, in $l$. That is

$$
\Delta V \approx 3 V_{0} \varepsilon
$$

Then absolute sorption amount can be obtained by substituting Eq. 7 and Eq. 9 into Eq. 6, and rearranged as:

$n_{a}=\frac{n_{e}+3 c V_{0} \varepsilon / \mathrm{m}_{c o a l}}{1-c / c_{a}}$

where the ratio of $c / c_{a}$ is the normalized sorbate concentration of bulk phase by the concentration of sorbed phase. The $c$ is obtained by equation of state (EOS) developed by Span and Wagner for $\mathrm{CO}_{2}[14]$ and by Setzmann and Wagner for $\mathrm{CH}_{4}$ [15]. The $c_{a}$ at sub-critical condition can be estimated by using the concentration of liquid state [16]. The $c_{a}$ at supercritical condition can be estimated by taking the reciprocal of parameter $b$ in van der Waals equation of state. The related values of $b$ and $c_{a}$ are listed in Table 2.

\section{Results and discussion}

\subsection{Sorption isotherms and modeling}

The sorption and swelling experiments for block coal samples were carried out simultaneously under $\mathrm{CO}_{2}$ and $\mathrm{CH}_{4}$ pressure up to $16 \mathrm{MPa}$ at 25,45 and $65^{\circ} \mathrm{C}$. The plots of the excess or absolute sorption amounts of sorbate $\left(n_{e}\right.$ or $\left.n_{a}\right)$ versus equilibrium pressure $(P)$ at the specified temperature, are known as the sorption isotherm and are shown in Figs. $2 \mathrm{a} 1$ and $2 \mathrm{~b} 1$. The values of $n_{e}$ and $n_{a}$ were calculated according to Eq. 5 and Eq. 10, respectively. The dotted and dashed lines trace the excess and absolute sorption data, respectively. 
The results are agreed with the common understanding. The patterns of sorption isotherms for the block samples are similar to that for the grain samples [17].

The excess sorption amount $n_{e}$ is less distinguished from the corresponding absolute sorption amount $n_{a}$ in the low pressure region, though $n_{e}$ is significantly lower than $n_{a}$ in the high pressure region. The excess sorption amount $n_{e}$ increases with the increase of pressure at the sub-critical condition. The increase of $n_{e}$ slows down and levels out or starts to decrease when the condition is near or passes the supercritical point. The supercritical points of $\mathrm{CO}_{2}$ and $\mathrm{CH}_{4}$ are $7.38 \mathrm{MPa} / 31.06^{\circ} \mathrm{C}$ and $4.59 \mathrm{MPa} /-82.6^{\circ} \mathrm{C}$, respectively.

Unlike the pattern of excess sorption isotherms, the absolute sorption amount $n_{a}$ increases with the increase of pressure in the whole pressure range studied. A type-II sorption pattern is observed: as the pressure increases, the increase rate of $n_{a}$ is faster initially when the sorbate coverage is low and the sorption activity is high, then slows down for a while, and speeds up again. This type-II sorption pattern indicates a multilayer sorption characteristic. It is more apparent with respect to the $\mathrm{CO}_{2}$ isotherms.

The sorption behavior is also studied by following the change of normalized sorbate concentration of bulk phase $\left(c / c_{a}\right)$, as shown in Figs. $2 \mathrm{a} 2$ and $2 \mathrm{~b} 2$, where $c_{a}$ is the sorbate concentration of sorbed phase. The ratio of $c / c_{a}$ measures the degree of sorption saturation. The lower the $c / c_{a}$ ratio is, the far from the saturation is. In other words, the low $c / c_{a}$ ratio is corresponding to more available sorption sites. Therefore, the change of $n_{a}$ is more sensitive with the change of $c / c_{a}$ at the low $c / c_{a}$ ratio region.

The BET sorption model was adopted, modified as shown in Eq.11 and applied to fit the $n_{a} \sim c / c_{a}$ data sets.

$\mathrm{n}_{\mathrm{a}}=\frac{n_{\mathrm{m}} a \mathrm{c} / c_{a}}{\left(1-\mathrm{c} / c_{a}\right)\left(1+(\mathrm{a}-1) \mathrm{c} / c_{a}\right)}$

where $n_{m}$ is defined as the sorption amount required to form a monolayer, adopted from the original BET model; $a$ the constant; $n_{a}=0$ at $c / c_{a}=0$, and $c<c_{a}$.

The solid lines in Figs. 2a 2 and $2 \mathrm{~b} 2$ illustrate the fitting results. The values of $n_{m}$ and $a$ are listed in Table 3 along with the corresponding values of determination coefficient $\left(R^{2}\right)$. The fittings are confirmed by the relatively high values of $R^{2}$ (0.94 1.00).

It can be seen that the case with low temperature, high rank coal as sorbent and $\mathrm{CO}_{2}$ as sorbate is corresponding to a higher monolayer sorption capacity. The uptake 
mechanism of small molecules, such as $\mathrm{CO}_{2}$ and $\mathrm{CH}_{4}$, by coal is still uncertain although it has been studied extensively. The words of sorption, imbibition and dissolution have been used for describing the uptake process. It is common understanding that the uptake process cannot be simply recognized as a conventional adsorption process, especially the condition under high pressure. The temperature dependency is agreed with the characteristic of physical sorption, while the sorbate dependency is agreed with the order of solubility parameter of the relevant materials.

The solubility parameter obtained through the thermodynamic calculation can be used to estimate the mutual dissolution ability of materials. The closer the solubility parameter is, the stronger the mutual interaction is. The solubility parameter for coal, $\mathrm{CO}_{2}, \mathrm{CH}_{4}, \mathrm{~N}_{2}$ and $\mathrm{He}$ are $\sim 25,15,12,9$ and $1 \mathrm{MPa}^{0.5}$, respectively [18]. The sorption characteristics of $\mathrm{N}_{2}$ and $\mathrm{He}$ are out of the range of this study. It is commonly known that the sorption ability of $\mathrm{N}_{2}$ on coal is less than that of $\mathrm{CO}_{2}$ or $\mathrm{CH}_{4}$. And $\mathrm{He}$ is usually considered as non-sorption gas with respect to coal. In fact, the surface area and total pore volume of coal measured by $\mathrm{N}_{2}$ are usually less than that measured by $\mathrm{CO}_{2}[19,20]$. Therefore, it can be acceptable that the sorption process involved with coal is not only the surface adsorption process.

Fig. $2 \mathrm{a} 3$ represents the relationship of the normalized absolute sorption amount $n_{a} / n_{m}$ versus the normalized concentration $c / c_{a}$ for all data collected. In comparison with the data shown in Figs 2a1, 2b1, 2a2 and 2b2, the differences among the test cases are declined. The solid line is the fitting result of the modified BET model (Eq.11) with $n_{d} / n_{m} \sim c / c_{a}$ data of all test cases. The corresponding parameter and $R^{2}$ are listed in Table 3. The differential characteristic of sorption process is illustrated in Fig. $2 b 3$.

The values of $c / c_{a}$ at $n_{a} / n_{m}=1$ are also listed in Table 3, which can be calculated according to Eq. 11 or read from Fig. 2a3. It shows that the concentration of bulk phase is still far from the concentration of sorbed phase when the monolayer sorption is approached $\left(\mathrm{c} / \mathrm{c}_{\mathrm{a}}=0.17\right.$, at $\left.n_{a} / n_{m}=1\right)$.

\subsection{Swelling isotherms}

Similarly, the swelling ratio of block coal sample $(\varepsilon)$ varies with the equilibrium pressure $(P)$. The plots of $\varepsilon$ versus $P$ at the specified temperature, known as swelling isotherms, are shown in Figs. $3 \mathrm{a} 1$ and $3 \mathrm{~b} 1$. It shows that the swelling ratio increases with the increase of pressure and decreases with the increase of temperature. A plateau at the high pressure region can be observed and a L-type pattern is more suitable to 
$5 \quad \varepsilon=\varepsilon_{m-L} \frac{h \cdot\left(\mathrm{c} / \mathrm{c}_{\mathrm{a}}\right)}{1+(h-1) \cdot\left(\mathrm{c} / \mathrm{c}_{\mathrm{a}}\right)}$

describe the isotherms.

Figs. $3 \mathrm{a} 2$ and $3 \mathrm{~b} 2$ are the plots of $\varepsilon$ versus $c / c_{a}$, the swelling ratio versus the normalized concentration. The Langmuir sorption model was adopted, modified as shown in Eq.12 and applied to fit the $\varepsilon \sim c / c_{a}$ data sets.

where $\varepsilon_{m-L}$ is defined as the maximum swelling ratio predicted by modified Langmuir model since $\varepsilon \rightarrow \varepsilon_{m-L}$ when $c / c_{a} \rightarrow 1 ; h$ the constant; $\varepsilon=0$ at $c / c_{a}=0$, and $c<c_{a}$.

The solid lines in Figs. $3 \mathrm{a} 2$ and $3 \mathrm{~b} 2$ are the fitting results. The predicted $\varepsilon_{m-L}$ and $h$ values are listed in Table 4 along with the corresponding values of $R^{2}$. The high values of $R^{2}(0.98 \sim 1.00)$ confirm the satisfied fittings.

It can be seen that the case with low temperature, high rank coal as sorbent and $\mathrm{CO}_{2}$ as sorbate is corresponding to a higher maximum swelling ratio $\left(\varepsilon_{m-L}\right)$. It is agreed with a higher monolayer sorption capacity $\left(n_{m}\right)$.

Fig. $3 \mathrm{a} 3$ is a plot of the normalized swelling ratio $\varepsilon / \varepsilon_{m-L}$ versus the normalized concentration $c / c_{a}$ for all data collected. The difference among the test cases is also declined. The solid line is the fitting result of the modified Langmuir model (Eq. 12) with all $\varepsilon / \varepsilon_{m} \sim c / c_{a}$ data. The corresponding parameters and $R^{2}$ are listed in Table 4 . The differential characteristic of swelling process with respect to concentration is illustrated in Fig. 3b3.

\subsection{Correlation between swelling and sorption}

\subsubsection{By a logistic function - modified Gompertz function}

In above sections, the swelling ratio is correlated with the sorbate pressure of bulk phase. However, the swelling of coal should be induced by the sorbate dissolved in coal or sorbed on coal (the coal bound sorbate) rather than the free sorbate in bulk phase though the amount of coal bound sorbate (absolute sorption amount $n_{a}$ ) is related to the concentration of sorbate in bulk phase.

Therefore, an attempt was made to correlate the swelling with the coal bound sorbate. The swelling ratio $\varepsilon$ is plotted versus the absolute sorption amounts $n_{a}$ in Figs. $4 \mathrm{a} 1$ and $4 \mathrm{~b} 1$ and plotted versus the sorption coverage $n_{d} / n_{m}$ in Figs. $4 \mathrm{a} 2$ and $4 \mathrm{~b} 2$, where $n_{m}$ is the monolayer sorption capacity obtained according to the modified BET model in Eq. 11.

Unlike the $\varepsilon \sim c / c_{a}$ isotherms, the $\varepsilon \sim n_{a}$ or $\varepsilon \sim n_{a} / n_{m}$ isotherms appear with S-type pattern. It can be seen that the initial stage of swelling is approximately exponential; 
then, as the degree of sorption coverage increases the swelling slows down, and shortly after the monolayer coverage achieves the swelling nearly stops. The modified Gompertz function (Eq.13), a logistic function and named as SGompertz in software Origin, is suitable to describe the isotherms and was applied to fit with the $\varepsilon \sim n_{d} / n_{m}$ data sets.

$$
\varepsilon=\varepsilon_{\mathrm{m}-\mathrm{G}} \cdot \exp \left(-\exp \left(-\mathrm{m}\left(\frac{\mathrm{n}_{\mathrm{a}}}{\mathrm{n}_{\mathrm{m}}}-x_{c}\right)\right)\right)
$$

where $\varepsilon_{m-G}$ is defined as the maximum swelling ratio predicted by the modified Gompertz function since $\varepsilon=\varepsilon_{m-G}$ when $n_{d} / n_{m} \rightarrow \infty ; m$ and $x_{c}$ the constant; and $\varepsilon \approx 0$ at $n_{a} / n_{m}=0$.

The solid lines in Figs. $4 \mathrm{a} 2$ and $4 \mathrm{~b} 2$ are the fitting results and confirmed with high $R^{2}$ values $(\sim 1.00)$. The values of $\varepsilon_{m-G}, h, x_{c}$ and $R^{2}$ are listed in Table 5. It can be noticed that the maximum swelling ratio predicted by Eqs. 12 and 13 is not exact the same but the relative standard deviation is in the range of $0.7 \% \sim 5.6 \%$.

Similarly, Fig. $4 \mathrm{a} 3$ is a plot of the normalized swelling ratio $\varepsilon / \varepsilon_{m-G}$ versus the normalized sorption amount $n_{d} / n_{m}$ for all data collected. By this way the difference among the test cases is declined. The solid line is the fitting result of the modified Gompertz function (Eq. 13) with all $\varepsilon / \varepsilon_{m-G} \sim n_{d} / n_{m}$ data. The corresponding parameters and $R^{2}$ are listed in Table 5. The differential characteristic of swelling process with respect to sorption amount is illustrated in Fig. $4 \mathrm{~b} 3\left(d\left(\varepsilon / \varepsilon_{m-G}\right) / d\left(n_{d} / n_{m}\right) \sim n_{d} / n_{m}\right)$.

The values of $\varepsilon / \varepsilon_{m-G}$ at $n_{d} / n_{m}=1$ calculated according to Eq. 13 or reading from Fig. $4 \mathrm{a} 3$ are listed in Table 5 as well. The values are in the range of 0.91 0.97, indicating that more than $90 \%$ of total swelling is related with the first layer sorption. It implies the importance of the mutual contact between coal and sorbate.

The parameter $x_{c}$ in Eq. 13 is the inflection point of $\varepsilon \sim n_{d} / n_{m}$ or $\varepsilon / \varepsilon_{m-G} \sim n_{d} / n_{m}$ profiles and the peak point of the corresponding differential profiles. The differential profile shown in Fig. $4 \mathrm{~b} 3$ reflects the sensitivity of $\varepsilon / \varepsilon_{m-G}$ with respect to the change of $n_{d} / n_{m}$. It shows that the degree of swelling sensitivity varies with the degree of sorbate coverage. The swelling sensitivity increases intially, reaches a maximum at $n_{d} / n_{m} \approx 0.37$, and the sensitivity approches to zero at $n_{d} / n_{m} \approx 1.5$. It should be attributed to the diversity of coal structure and the possible influence from the swollen molecules.

\subsubsection{By a theoretical model}

Chemically, the structure of coal is described as a cross-linked macromolecular 
network. The linkage may be covalent bonds, non-covalent bonds (such as hydrogen bond, ionic bond, hydrophobic attractions and intermolecular forces, including Van der Waals forces and dipole-dipole attraction and London forces). The small molecules can get into the cross-linked macromolecular network and be trapped or dissolved inside the coal molecule. It results in the dissociation of non-covalent linkage. Consequently, the surface free energy is reduced, and the geometry structure of coal is relaxed.

An attempt was made to correlate the swelling ratio with the sorption related parameters theoretically. The swelling ratio is assumed to be proportional to the change of Gibbs free energy induced by sorption [21]:

$\varepsilon=\frac{S A \rho}{\mathrm{E}} \Phi$

where $A$ is dimensionless constant; $E$ Young's modulus of coal, in $P a$; $\rho$ the density of coal, in $\mathrm{kg} / \mathrm{m}^{3} ; S$ the specific surface area of coal, in $\mathrm{m}^{2} / \mathrm{m}^{3}$ and $\Phi$ the change of Gibbs free energy induced by sorption, in $J /\left(\mathrm{kg} \cdot \mathrm{m}^{2} / \mathrm{m}^{3}\right) . \Phi$ is calculated according to Eq. 15 [22]:

$\Phi=\frac{1}{1000 \mathrm{~S}} \int_{0}^{\mathrm{P}} \mathrm{n}_{\mathrm{a}}\left(\frac{1}{c}-\frac{1}{c_{a}}\right) d P$

The relationship between $P$ and $c$ is correlated by the Equation of State as follows:

$$
P=1000 z c R T=1000(e c+1) c R T
$$

where $c$ is the sorbate concentration of bulk phase, in $m o l / l ; P$ the sorbate pressure of bulk phase in $\mathrm{Pa} ; \mathrm{R}$ the universal gas constant, setting as $8.314 \mathrm{~J} /(\mathrm{mol} \cdot \mathrm{k})$; $T$ the temperature, in $K ; z$ the compressibility factor of sorbate, estimated by a linear function of $z=e c+1$ and $e$ the constant, in $l / m o l$.

Taking Eqs. 11 and 16 into account, the Eq. 15 can be rewritten as Eq. 17:

$$
\Phi=\frac{\mathrm{RT}_{m} a}{\mathrm{Sc}_{\mathrm{a}}} \int_{0}^{\mathrm{c}} \frac{2 \mathrm{ec}+1}{1+(\mathrm{a}-1) \frac{\mathrm{c}}{\mathrm{c}_{\mathrm{a}}}} d c
$$

Integrating Eq. 17 from 0 to $c$ to obtain $\Phi$ and substituting the results into Eq. 14, a mathematic relationship between the swelling ratio and the normalized concentration is established:

$$
\varepsilon=D G \frac{\mathrm{c}}{c_{a}}+\mathrm{D}\left(1-\frac{G}{F}\right) \ln \left(1+F \frac{c}{c_{a}}\right)
$$


where $\mathrm{D}=\frac{A \rho \mathrm{RT} n_{m} a}{\mathrm{E}(\mathrm{a}-1)}, G=2 e c_{a}, F=a-1$ and $c<c_{a}$.

According to Eq. 11 the ratio of $c / c_{a}$ can also be expressed as Eq. 19:

$$
\frac{\mathrm{c}}{c_{a}}=\frac{\sqrt{\left(\frac{(F+1) n_{m}}{n_{a}}+1-\mathrm{F}\right)^{2}+4 \mathrm{~F}}-\frac{(F+1) n_{m}}{n_{a}}-1+\mathrm{F}}{2 F}
$$

Then the relationship between $\varepsilon$ and $n_{d} / n_{m}$ can be written as Eq. 20:

$$
\begin{aligned}
& \varepsilon=\frac{D G}{2 \mathrm{~F}}\left[\sqrt{\left(\frac{(F+1) n_{m}}{n_{a}}+1-\mathrm{F}\right)^{2}+4 \mathrm{~F}}-\frac{(F+1) n_{m}}{n_{a}}-1+\mathrm{F}\right]+ \\
& \mathrm{D}\left(1-\frac{G}{F}\right) \ln \left(1+\frac{1}{2}\left[\sqrt{\left(\frac{(F+1) n_{m}}{n_{a}}+1-\mathrm{F}\right)^{2}+4 \mathrm{~F}}-\frac{(F+1) n_{m}}{n_{a}}-1+\mathrm{F}\right)\right]
\end{aligned}
$$

The parameters $G$ and $F$ are groups of constants and can be calculated according to their definitions. The parameter $D$ includes constants and physical properties of coal, which should be able to calculate for the specified conditions theoretically. Then the swelling ratio can be obtained through mathematical calculation. Unfortunately, the parameter $D$ is not able to obtain at present, because the parameter $A$ in the expression of $D$ are hardly obtained. Therefore, experimental data match for $D$ was carried out to evaluate the applicability of Eq. 20.

The solid lines in Fig. 5a and Fig. 5b are the fitting results when $D$ is considered to be variable. The values of $D, G$ and $F$ are listed in Table 6 along with the coefficient of determination $\left(R^{2}\right)$. The fitting curves of $\varepsilon \sim n_{d} / n_{m}$ present $S$-type pattern and the results are generally acceptable with the $R^{2}$ in the range of $0.85 \sim 1.00$. The fitting results are slightly lower than experimental data before monolayer sorption coverage is completed $\left(n_{d} / n_{m} \leq 1\right)$, while they are slightly higher than experimental data after monolayer sorption coverage is completed $\left(n_{d} / n_{m}>1\right)$. This may be because the linear relationship between swelling ratio and change of Gibbs free energy (Eq. 14) should not work for the whole sorption coverage.

According to the results of $D$ in Table 6, the parameter $A$ can be estimated through the expression of $D$. It is reasonable to assume Young's modulus $E$ and density $\rho$ of the studied high rank coals to be $3.5 \mathrm{GPa}$ and $1350 \mathrm{~kg} / \mathrm{m}^{3}$, respectively. The results of the calculated $A$ are listed in Table 7. It is encouraged that the values of $A$ are similar for all the supercritical conditions and the average value is 149. However, the values of $A$ at free gas condition (such as $\mathrm{CO}_{2}$ at $25^{\circ} \mathrm{C}$ ) is much higher than that at 
supercritical conditions. This implies that the phase state of sorbate may affect the interaction between coal and sorbate, and in turn, influence the degree of swelling of coal. The value and physical meaning of $A$ requires further verified and confirmed by more experimental data.

\section{Conclusions}

The swelling and sorption behaviors of two block coal samples under $\mathrm{CO}_{2}$ and $\mathrm{CH}_{4}$ pressure (up to $16 \mathrm{MPa}$ ) was investigated experimentally and theoretically. The swelling ratio and excess sorption amount of block coal sample were measured simultaneously. The absolute sorption amounts were calculated and correlated with the corresponding swelling ratios. The main conclusions are summarized as the following:

(1) Absolute sorption isotherms $\left(n_{a} \sim c / c_{a}\right)$ of two block coal samples under $\mathrm{CO}_{2}$ and $\mathrm{CH}_{4}$ pressure present type-II sorption pattern, indicating multilayer sorption characteristic. The isotherms can be fitted well with the modified BET model.

(2) Swelling isotherms $\left(\varepsilon \sim c / c_{a}\right)$ of two block coal samples under $\mathrm{CO}_{2}$ and $\mathrm{CH}_{4}$ pressure show $L$-type pattern. The isotherms can be fitted well with the modified Langmuir model. The maximum swelling ratio is in the range of $0.44 \% \sim 0.93 \%$. The case with low temperature, QS coal as sorbent and $\mathrm{CO}_{2}$ as sorbate has the highest monolayer sorption capacity and highest swelling ratio.

(3) The relationship between swelling and sorption coverage $\left(\varepsilon \sim n_{d} / n_{m}\right)$ presents $S$-type pattern, and was suitable to be expressed by the modified Gompertz function. Generally, when the monolayer sorption coverage $\left(n_{a} / n_{m}=1\right)$ is approached, the swelling ratio equals to $\sim 93 \%$ of the maximum swelling ratio. It implies the importance of the mutual contact between coal and sorbate. The differential characteristic of the swelling process shows that the sensitivity of degree of swelling varies with the degree of sorbate coverage. The modified Gompertz function can be used to predict the swelling behavior of coal from the sorption data.

(4) It is interesting to find that the correlations of normalized properties $\left(n_{a} / n_{m} \sim c / c_{a}\right.$, $\varepsilon / \varepsilon_{m-L} \sim c / c_{a}$ and $\left.\varepsilon / \varepsilon_{m-G} \sim n_{a} / n_{m}\right)$ have a single relationship that is indendent of experimental conditions, sorbates and coal types. It may indicate the consistency of sorption and swelling mechanism under the experimental conditions. 
1 (5) A theoretical model was established to predict the swelling data from sorption data. The concept of reduction of surface energy by sorption was taken into account. The results of experiment data match are generally acceptable.

\section{Acknowledgements}

The authors gratefully acknowledge the financial support from the National Science Foundation of China (21176244) and the Science Foundation of Zhejiang Province,

China (LQ13B060009).

\section{References}

[1] Bergen Fv, Pagnier H and Krzystolik P. Field experiment of enhanced coalbed methane- $\mathrm{CO}_{2}$ in the upper Silesian basin of Poland. Environ. Geol. 2006, 13, 201-224.

[2] Day S, Fry R and Sakurovs R. Swelling of Australian coals in supercritical $\mathrm{CO}_{2}$. Int. J. Coal Geol. 2008, 74, 41-52.

[3] St George JD and Barakat MA. The change in effective stress associated with shrinkage from gas desorption in coal. Int. J. Coal Geol. 2001, 45, 105-113.

[4] Kelemen SR and Kwiatek LM. Physical properties of selected block Argonne Premium bituminous coal related to $\mathrm{CO}_{2}, \mathrm{CH}_{4}$, and $\mathrm{N}_{2}$ adsorption. Int. J. Coal Geol. 2009, 77, 2-9.

[5] Day S, Fry R and Sakurovs R. Swelling of coals by supercritical gases and its relationship to sorption. Energy Fuels 2010, 24, 2777-2783.

[6] Walker PL, Verma SK and Rivera-Utrilla J. A direct measurement of expansion in coals and macerals induced by carbon dioxide and methanol. Fuel, 1988, 67: 719-726

[7] Pan Z, Connell L D. A theoretical model for gas adsorption-induced coal swelling. International Journal of Coal Geology, 2007, 69: 243-252.

[8] Hsieh ST, Duda JL. Probing coal structure with organic vapor sorption. Fuel 1987, 66, 170-178.

[9] Kelemen SR, Kwiatek LM. Physical properties of selected block Argonne Premium bituminous coal related to $\mathrm{CO}_{2}, \mathrm{CH}_{4}$ and $\mathrm{N}_{2}$ adsorption. Int $\mathrm{J}$ Coal Geol 2009, 77: 2-9.

[10] Day S, Fry R, Sakurovs R. Swelling of Australian coals in supercritical $\mathrm{CO}_{2}$. Int J Coal Geol, 2008, 74: 41-52.

[11] Cui X, Bustin RM, Chikatamarla L. Adsorption-induced coal swelling stress: Implications for methane production and acid gas sequestration into coal seams. 
J Geophys Res, 2007, 112, No. B10202.

[12] Chikatamarla L, Cui X, Bustin R M. Implications of volumetric swelling /shrinkage of coal in sequestration of acid gases. 2004 International Coalbed Methane Symposium Proceedings. Tuscaloosa, Alabama, 2004.

[13] Chen GQ, Yang JL and Liu ZY. Method for simultaneous measure of sorption and swelling of the coal block under high gas pressure. Energy \& Fuels, 2012, 26 (7): 4583-4589.

[14] Span R, Wagner W. A new equation of state for carbon dioxide covering the fluid region from the triple-point temperature to $1100 \mathrm{~K}$ at pressures up to 800 MPa. J Phys Chem Ref Data 1996, 25(6):1509-1596.

[15] Setzmann U, Wagner W. A new equation of state and tables of thermodynamic properties for methane covering the range from the melting line to $625 \mathrm{~K}$ at pressures up to $1000 \mathrm{MPa}$. J Phys Chem Ref Data, 1991, 20: 1061-1155.

[16] National institute of standards and technology (nist) chemistry webbook. Http://webbook.Nist.Gov/chemistry/fluid/ (accessed January 19, 2012).

[17] Han FS, Busch A, Krooss BM, Liu ZY, Yang JL. $\mathrm{CH}_{4}$ and $\mathrm{CO}_{2}$ sorption isotherms and kinetics for different size fractions of two coals. Fuel, 2013, 108 : 137-142.

[18] Chang HY, Zhang DX, Han WY and Gao JS. Coal swelling behavior in solvents at different temperatures. Journal of East China University of Science and Technology, 2004, 30(4): 406-409. (In Chinese)

[19] Gan H, Nandi SP, Walker PLJr. Nature of the porosity in American coals. Fuel, 1972, 51: 272.

[20] Walker PLJr, Kini KA. Measurement of the ultrafine surface area of coals. Fuel, 1965, 44: 453.

[21] Adamson AW. Physical Chemistry of Surfaces (Volume One). Beijing: Science Press, 1984.

[22] Toth J. Adsorption: theory, modelling, and analysis. 2002-05-10. Publisher: CRC / Marcel Dekker 2002. 


\section{TABLES}

2 Table 1 Properties of YQ and QS coals

3 Table 2 Values of parameter $b$ in van der Waals equation of state and values used as concentration of sorbed phase $c_{a}$

5 Table 3 Parameters $n_{m}$ and $a$ obtained from fitting of modified BET model with absolute sorption isotherms and corresponding $R^{2}$

Table 4 Parameter $\varepsilon_{m-L}$ and $h$ obtained from fitting of modified Langmuir model with

8

4

30

1
swelling isotherms and corresponding $R^{2}$

Table 5 Parameters $\varepsilon_{m-G}, x_{c}$ and $m$ obtained from fitting of modified Gompertz function with swelling $\sim$ sorption data and corresponding $R^{2}$

Table 6 Parameters $G$ and $F$ calculated and parameter $D$ obtained from experiment data match of theoretical model and corresponding $R^{2}$

Table 7 Parameter $A$ obtained according to the expression of parameter $D$

6

17

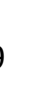



2

23

5

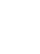

8

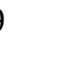




\section{FIGURES}

Figure 1 Schematic diagram of the experimental setup for measuring sorption and swelling of block coal sample

Figure 2 Sorption isotherms of block coal samples and modeling. a1 and b1: excess and absolute sorption amount $\left(n_{e}\right.$ and $\left.n_{\mathrm{a}}\right)$ vs. equilibrium pressure $(P) ; \mathrm{a} 2$ and $\mathrm{b} 2$ : absolute sorption amount $\left(n_{\mathrm{a}}\right)$ vs. normalized concentration of bulk phase by concentration of sorbed phase $\left(c / c_{\mathrm{a}}\right)$; a3: normalized absolute sorption amount by monolayer sorption amount $\left(n_{d} / n_{m}\right)$ vs. normalized concentration of bulk phase by that of sorbed phase $\left(c / c_{a}\right)$; b3: rate of change of $n_{a} / n_{\mathrm{m}}$ with respect to $c / c_{a}$. Filled and unfilled symbols: experimental data of YQ and QS samples; dotted and dashed lines: excess and absolute sorption isotherms; solid lines: fitting results of modified BET model with absolute sorption isotherms; square, triangle and circle symbols: 25,45 and $65^{\circ} \mathrm{C}$

Figure 3 Swelling isotherms of block coal samples and modeling. a1 and b1: swelling ratio $(\varepsilon)$ vs. equilibrium pressure $(P)$; a2 and b2: swelling ratio $(\varepsilon)$ vs. normalized concentration of bulk phase by that of sorbed phase $\left(c / c_{a}\right)$; a3: normalized swelling ratio by maximum swelling ratio predicted by modified Langmuir model $\left(\varepsilon / \varepsilon_{m-L}\right) \quad$ vs. normalized concentration of bulk phase by that of sorbed phase $\left(c / c_{a}\right)$; b3: rate of change of $\varepsilon / \varepsilon_{m-L}$ with respect to $c / c_{a}$. Filled and unfilled symbols: experimental data of YQ and QS samples; solid lines: fitting results of modified Langmuir model; square, triangle and circle symbols: 25,45 and $65^{\circ} \mathrm{C}$

Figure 4 Correlation of swelling and sorption data for block coal samples. a1 and b1: swelling ratio $(\varepsilon)$ vs. absolute sorption amount $\left(n_{a}\right)$; a2 and b2: swelling ratio $(\varepsilon)$ vs. normalized absolute sorption amount by monolayer sorption capacity $\left(n_{d} / n_{m}\right)$; a3: normalized swelling ratio by maximum swelling ratio predicted by modified Gompertz model $\left(\varepsilon / \varepsilon_{m-G}\right)$ vs. normalized absolute sorption amount by monolayer sorption amount $\left(n_{a} / n_{m}\right)$; b3: rate of change of $\varepsilon / \varepsilon_{m-G}$ with respect to $n_{a} / n_{m}$. Filled and unfilled symbols: experimental data of YQ and QS samples; solid lines: fitting results of modified Gompertz function; square, triangle and circle symbols: 25,45 and $65^{\circ} \mathrm{C}$

Figure 5 Experiment data match of theoretical model with one adjustable parameter. Filled and unfilled symbols: experimental data of YQ and QS samples; solid lines: fitting results; square, triangle and circle symbols: 25,45 and $65^{\circ} \mathrm{C}$ 


\begin{tabular}{|c|c|c|c|c|c|c|c|c|c|}
\hline \multirow{2}{*}{ Coal } & \multirow{2}{*}{$\mathrm{V}_{\mathrm{R}}$} & \multicolumn{3}{|c|}{ Proximate analysis $/ \mathrm{w} \%$} & \multicolumn{5}{|c|}{ Ultimate analysis /w\%, daf } \\
\hline & & $\mathrm{M}_{\mathrm{ad}}$ & $\mathrm{A}_{\mathrm{d}}$ & $\mathrm{V}_{\text {daf }}$ & $\mathrm{C}$ & $\mathrm{H}$ & $\mathrm{O}^{*}$ & $\mathrm{~N}$ & $S$ \\
\hline YQ & 2.3 & 0.9 & 15.6 & 8.4 & 88.7 & 2.9 & 5.1 & 1.1 & 2.2 \\
\hline QS & 2.5 & 1.7 & 8.4 & 6.5 & 92.3 & 2.9 & 3.5 & 0.9 & 0.3 \\
\hline
\end{tabular}

$2 \quad V_{R}$ : vitrinite reflectance; $M_{a d}:$ moisture on the air-dried basis; $A_{d}$ : ash on the dry basis; $V_{d a f}$ : volatile

3 on the dry-ash-free basis; daf: dry-ash-free basis; S: total sulfur; ${ }^{*}$ by difference.

4

5

6

7

8

9

10

11

12

13

14

15

16

17

18

19

20

21

22

23

24

25

26

27 
1 Table 2 Values of parameter $b$ in van der Waals equation of state and values used as concentration

2

4

6

8

9

10

11

12

13

14

15

16

17

18

19

20

21

22

23

24

25

26

27

28

29

30

31

32

33

34

$$
\text { of sorbed phase } c_{a}
$$

\begin{tabular}{lccc}
\hline & Temperature $\left[{ }^{\circ} \mathrm{C}\right]$ & $b[1 / \mathrm{mol}]$ & $c_{a}[\mathrm{~mol} / 1]$ \\
\hline $\mathrm{CO}_{2}$ & 25 & - & 16.144 \\
$\mathrm{CO}_{2}$ & $45-65$ & $4.267 \times 10^{-2}$ & 23.436 \\
$\mathrm{CH}_{4}$ & $25-65$ & $4.278 \times 10^{-2}$ & 23.375 \\
\hline
\end{tabular}

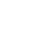

0

2

3

5

6

17

8

9

0

1

3


Table 3 Parameters $n_{m}$ and $a$ obtained from fitting of modified BET model with absolute sorption

2 isotherms and corresponding $R^{2}$

\begin{tabular}{|c|c|c|c|c|c|c|c|c|c|}
\hline \multirow[b]{2}{*}{ coal } & \multirow[b]{2}{*}{$\begin{array}{c}\text { temperature } \\
{\left[{ }^{\circ} \mathrm{C}\right]}\end{array}$} & \multicolumn{5}{|c|}{$\mathrm{CO}_{2}$} & \multicolumn{3}{|c|}{$\mathrm{CH}_{4}$} \\
\hline & & $\begin{array}{c}\mathrm{n}_{\mathrm{m}} \\
{[\mathrm{mol} / \mathrm{kg}]}\end{array}$ & $\mathrm{a}$ & $\mathrm{R}^{2}$ & $\begin{array}{c}\mathrm{c} / \mathrm{c}_{\mathrm{a}} \text { at } \\
\mathrm{n}_{\mathrm{a}} / \mathrm{n}_{\mathrm{m}} \\
=1\end{array}$ & $\begin{array}{c}\mathrm{n}_{\mathrm{m}} \\
{[\mathrm{mol} / \mathrm{kg}]}\end{array}$ & $\mathrm{a}$ & $\mathrm{R}^{2}$ & $\begin{array}{c}\mathrm{c} / \mathrm{c}_{\mathrm{a}} \text { at } \\
\mathrm{n}_{\mathrm{a}} / \mathrm{n}_{\mathrm{m}}=1\end{array}$ \\
\hline \multirow{3}{*}{ QS } & 25 & 3.41 & 18.31 & 0.94 & 0.19 & 2.87 & 19.61 & 0.98 & 0.18 \\
\hline & 45 & 3.30 & 28.70 & 0.94 & 0.16 & 2.59 & 16.32 & 0.97 & 0.20 \\
\hline & 65 & 2.70 & 36.74 & 0.98 & 0.14 & 2.26 & 15.66 & 0.96 & 0.20 \\
\hline \multirow{3}{*}{ YQ } & 25 & 2.78 & 25.13 & 0.97 & 0.17 & 2.35 & 13.03 & 0.96 & 0.22 \\
\hline & 45 & 2.65 & 30.10 & 1.00 & 0.15 & 1.97 & 16.80 & 0.97 & 0.20 \\
\hline & 65 & 2.45 & 23.23 & 0.99 & 0.17 & 1.67 & 20.45 & 0.98 & 0.18 \\
\hline \multicolumn{2}{|c|}{ All $n_{a} / n_{m} \sim c / c_{a}$ data } & \multicolumn{6}{|c|}{$\mathrm{a}=24.0, \mathrm{R}^{2}=0.96, \mathrm{c} / \mathrm{c}_{\mathrm{a}}=0.17$ at $\mathrm{n}_{\mathrm{a}} / \mathrm{n}_{\mathrm{m}}=1$} & & \\
\hline
\end{tabular}

3

4

5

6

7

8

9

10

11

12

13

14

15

16

17

18

19

20

21

22

23

24

25

26 
1 Table 4 Parameter $\varepsilon_{m-L}$ and $h$ obtained from fitting of modified Langmuir model with swelling 2 isotherms and corresponding $R^{2}$

\begin{tabular}{|c|c|c|c|c|c|c|c|}
\hline \multirow{2}{*}{ coal } & \multirow{2}{*}{$\begin{array}{c}\text { temperature } \\
{\left[{ }^{\circ} \mathrm{C}\right]} \\
\end{array}$} & \multicolumn{3}{|c|}{$\mathrm{CO}_{2}$} & \multicolumn{3}{|c|}{$\mathrm{CH}_{4}$} \\
\hline & & $\varepsilon_{\mathrm{m}-\mathrm{L} / \%}$ & $\mathrm{~h}$ & $\mathrm{R}^{2}$ & $\varepsilon_{\mathrm{m}-\mathrm{L} / \%}$ & $\mathrm{~h}$ & $\mathrm{R}^{2}$ \\
\hline \multirow{3}{*}{ QS } & 25 & 0.93 & 31.93 & 1.00 & 0.61 & 27.41 & 1.00 \\
\hline & 45 & 0.80 & 41.08 & 1.00 & 0.56 & 22.37 & 1.00 \\
\hline & 65 & 0.76 & 28.40 & 1.00 & 0.51 & 19.36 & 1.00 \\
\hline \multirow{3}{*}{ YQ } & 25 & 0.83 & 32.07 & 1.00 & 0.54 & 23.11 & 1.00 \\
\hline & 45 & 0.72 & 50.24 & 0.98 & 0.47 & 22.70 & 0.99 \\
\hline & 65 & 0.69 & 31.94 & 0.98 & 0.44 & 20.48 & 0.98 \\
\hline \multicolumn{2}{|c|}{ All $\varepsilon / \varepsilon_{m-L^{L}} \sim / c_{a}$ data } & & \multicolumn{5}{|c|}{$h=29.00, R^{2}=0.97$} \\
\hline
\end{tabular}

3

4

5

6

7

8

9

10

11

12

13

14

15

16

17

18

19

20

21

22

23

24

25

26

27 
1 Table 5 Parameters $\varepsilon_{m-G}, x_{c}$ and $m$ obtained from fitting of modified Gompertz function with

2 swelling sorption data and corresponding $R^{2}$

\begin{tabular}{|c|c|c|c|c|c|c|c|c|c|c|c|}
\hline \multirow{3}{*}{ coal } & \multirow{3}{*}{$\begin{array}{c}\text { temperature } \\
{\left[{ }^{\circ} \mathrm{C}\right]}\end{array}$} & \multicolumn{4}{|c|}{$\mathrm{CO}_{2}$} & \multicolumn{6}{|c|}{$\mathrm{CH}_{4}$} \\
\hline & & & & & & $\varepsilon / \varepsilon_{\mathrm{m}-\mathrm{G}}$ & & & & & $\varepsilon / \varepsilon_{\mathrm{m}-\mathrm{G}}$ \\
\hline & & $\varepsilon_{\mathrm{m}-\mathrm{G}}$ & $x_{c}$ & $\mathrm{~m}$ & $\mathrm{R}^{2}$ & $\begin{array}{c}\text { at } \\
\mathrm{n}_{\mathrm{a}} / \mathrm{n}_{\mathrm{m}} \\
=1 \\
=1\end{array}$ & $\varepsilon_{\mathrm{m}-\mathrm{G}}$ & $\mathrm{x}_{\mathrm{c}}$ & $\mathrm{m}$ & $\mathrm{R}^{2}$ & $\begin{array}{c}\text { at } \\
\mathrm{n}_{\mathrm{a}} / \mathrm{n}_{\mathrm{m}} \\
=1\end{array}$ \\
\hline \multirow{3}{*}{ QS } & 25 & 0.88 & 0.40 & 5.56 & 1.00 & 0.97 & 0.60 & 0.40 & 4.16 & 1.00 & 0.92 \\
\hline & 45 & 0.79 & 0.39 & 4.72 & 1.00 & 0.95 & 0.52 & 0.33 & 3.95 & 1.00 & 0.93 \\
\hline & 65 & 0.68 & 0.45 & 4.48 & 1.00 & 0.92 & 0.47 & 0.35 & 4.00 & 1.00 & 0.93 \\
\hline \multirow{3}{*}{ YQ } & 25 & 0.78 & 0.41 & 4.68 & 1.00 & 0.94 & 0.52 & 0.28 & 3.60 & 1.00 & 0.93 \\
\hline & 45 & 0.73 & 0.40 & 3.99 & 1.00 & 0.91 & 0.46 & 0.35 & 3.58 & 1.00 & 0.91 \\
\hline & 65 & 0.64 & 0.41 & 3.98 & 1.00 & 0.91 & 0.41 & 0.48 & 4.45 & 1.00 & 0.91 \\
\hline \multicolumn{4}{|c|}{ All $\varepsilon / \varepsilon_{m-G} \sim n_{d} / n_{m}$ data } & \multicolumn{8}{|c|}{$\mathrm{x}_{\mathrm{c}}=0.37, \mathrm{~m}=4.30, \mathrm{R}^{2}=0.97, \varepsilon / \varepsilon_{\mathrm{m}-\mathrm{G}}=0.93$ at $\mathrm{n}_{\mathrm{a}} / \mathrm{n}_{\mathrm{m}}=1$} \\
\hline
\end{tabular}

3

4

5

6

7

8

9

10

11

12

13

14

15

16

17

18

19

20

21

22

23

24

25 
Table 6 Parameters $G$ and $F$ calculated and parameter $D$ obtained from experiment data match of

2

\begin{tabular}{|c|c|c|c|c|c|c|c|c|c|}
\hline \multirow{2}{*}{ coal } & \multirow{2}{*}{$\begin{array}{c}\text { temperature } \\
{\left[{ }^{\circ} \mathrm{C}\right]}\end{array}$} & \multicolumn{4}{|c|}{$\mathrm{CO}_{2}$} & \multicolumn{4}{|c|}{$\mathrm{CH}_{4}$} \\
\hline & & $\mathrm{D}$ & $\mathrm{G}$ & F & $\mathrm{R}^{2}$ & D & $\mathrm{G}$ & $\mathrm{F}$ & $\mathrm{R}^{2}$ \\
\hline \multirow{3}{*}{ QS } & 25 & 0.80 & -3.40 & 17.31 & 0.94 & 0.42 & -1.38 & 18.61 & 0.90 \\
\hline & 45 & 0.48 & -2.21 & 25.09 & 0.98 & 0.42 & -1.16 & 15.32 & 0.94 \\
\hline & 65 & 0.41 & -2.51 & 35.74 & 0.98 & 0.38 & -0.96 & 14.66 & 0.95 \\
\hline \multirow{3}{*}{ YQ } & 25 & 0.60 & -3.40 & 24.13 & 0.92 & 0.45 & -1.38 & 12.03 & 0.85 \\
\hline & 45 & 0.42 & -2.21 & 29.10 & 0.86 & 0.33 & -1.16 & 15.8 & 0.94 \\
\hline & 65 & 0.41 & -2.51 & 35.75 & 0.92 & 0.27 & -0.96 & 19.45 & 1.00 \\
\hline
\end{tabular}

3

4

5

6

7

8

9

10

11

12

13

14

15

16

17

18

19

20

21

22

23

24

25

26

27

28 
Table 7 Parameter $A$ obtained according to the expression of parameter $D$

\begin{tabular}{ccccccc}
\hline coal & $\begin{array}{c}\text { temperature } \\
{\left[{ }^{\circ} \mathrm{C}\right]}\end{array}$ & $\begin{array}{c}\rho \\
{\left[\mathrm{kg} / \mathrm{m}^{3}\right]}\end{array}$ & $\begin{array}{c}\mathrm{E} \\
{[\mathrm{GPa}]}\end{array}$ & $\begin{array}{c}\mathrm{A} \\
\text { for } \mathrm{CO}_{2}\end{array}$ & $\begin{array}{c}\mathrm{A} \\
\text { for } \mathrm{CH}_{4}\end{array}$ & $\begin{array}{c}\text { average value } \\
\text { of A at all } \\
\text { supercritical } \\
\text { conditions }\end{array}$ \\
\hline \multirow{3}{*}{$\mathrm{QS}$} & 25 & 1350 & 3.5 & 232 & 145 & \\
& 45 & 1350 & 3.5 & 138 & 149 & \\
& 65 & 1350 & 3.5 & 136 & 145 & 149 \\
& 25 & 1350 & 3.5 & 217 & 185 & \\
$\mathrm{YQ}$ & 45 & 1350 & 3.5 & 150 & 154 & \\
& 65 & 1350 & 3.5 & 148 & 142 & \\
\hline
\end{tabular}

2

3

4

5

6

7

8

9

10

11

12

13

14

15

16

17

18

19

20

21

22

23

24

25

26 
9

10

11

12

13

14

15

16

17

18

19

20

21

22

23

24

25

26

27

28

29

30

31

32

33

34

35

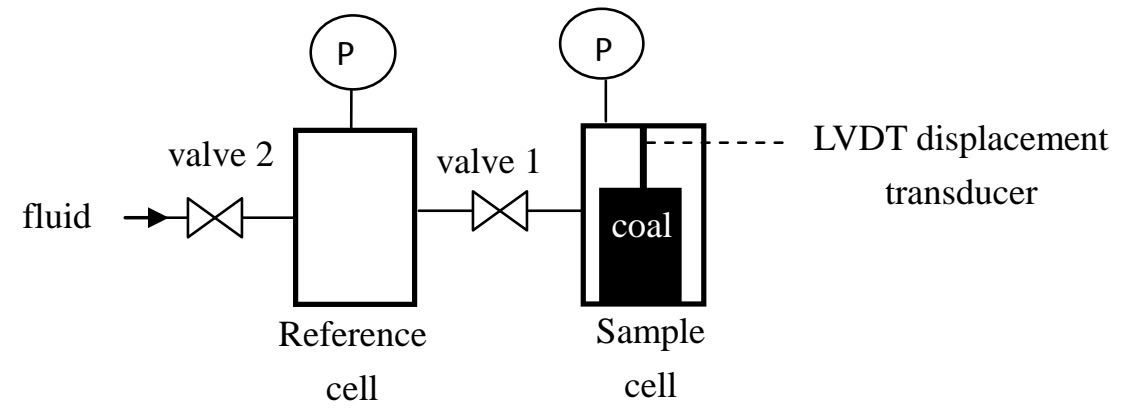

Fig. 1 Schematic diagram of experimental setup for measuring sorption and swelling of block coal sample 

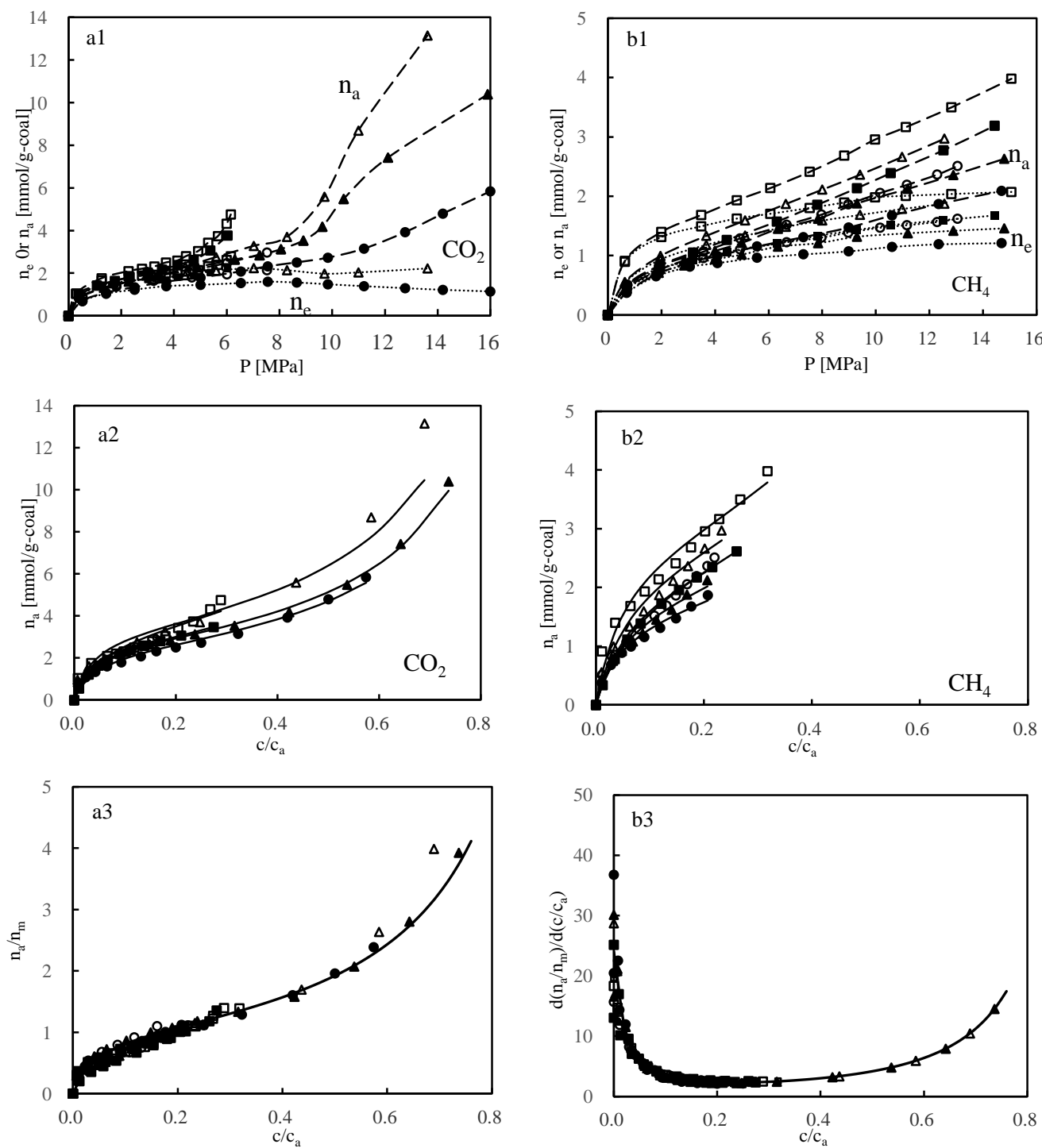

Fig. 2 Sorption isotherms of block coal samples and modeling. a1 and b1: excess and absolute sorption amount $\left(n_{e}\right.$ and $\left.n_{\mathrm{a}}\right)$ vs. equilibrium pressure $(P)$; $\mathrm{a} 2$ and $\mathrm{b} 2$ : absolute sorption amount $\left(n_{\mathrm{a}}\right)$ vs. normalized concentration of bulk phase by concentration of sorbed phase $\left(c / c_{\mathrm{a}}\right)$; a3: normalized absolute sorption amount by monolayer sorption amount $\left(n_{d} / n_{m}\right)$ vs. normalized concentration of bulk phase by that of sorbed phase $\left(c / c_{a}\right)$; b3: rate of change of $n_{d} / n_{\mathrm{m}}$ with respect to $c / c_{a}$. Filled and unfilled symbols: experimental data of YQ and QS samples; dotted and dashed lines: excess and absolute sorption isotherms; solid lines: fitting results of modified BET model with absolute sorption isotherms; square, triangle and circle symbols: 25,45 and $65^{\circ} \mathrm{C}$ 

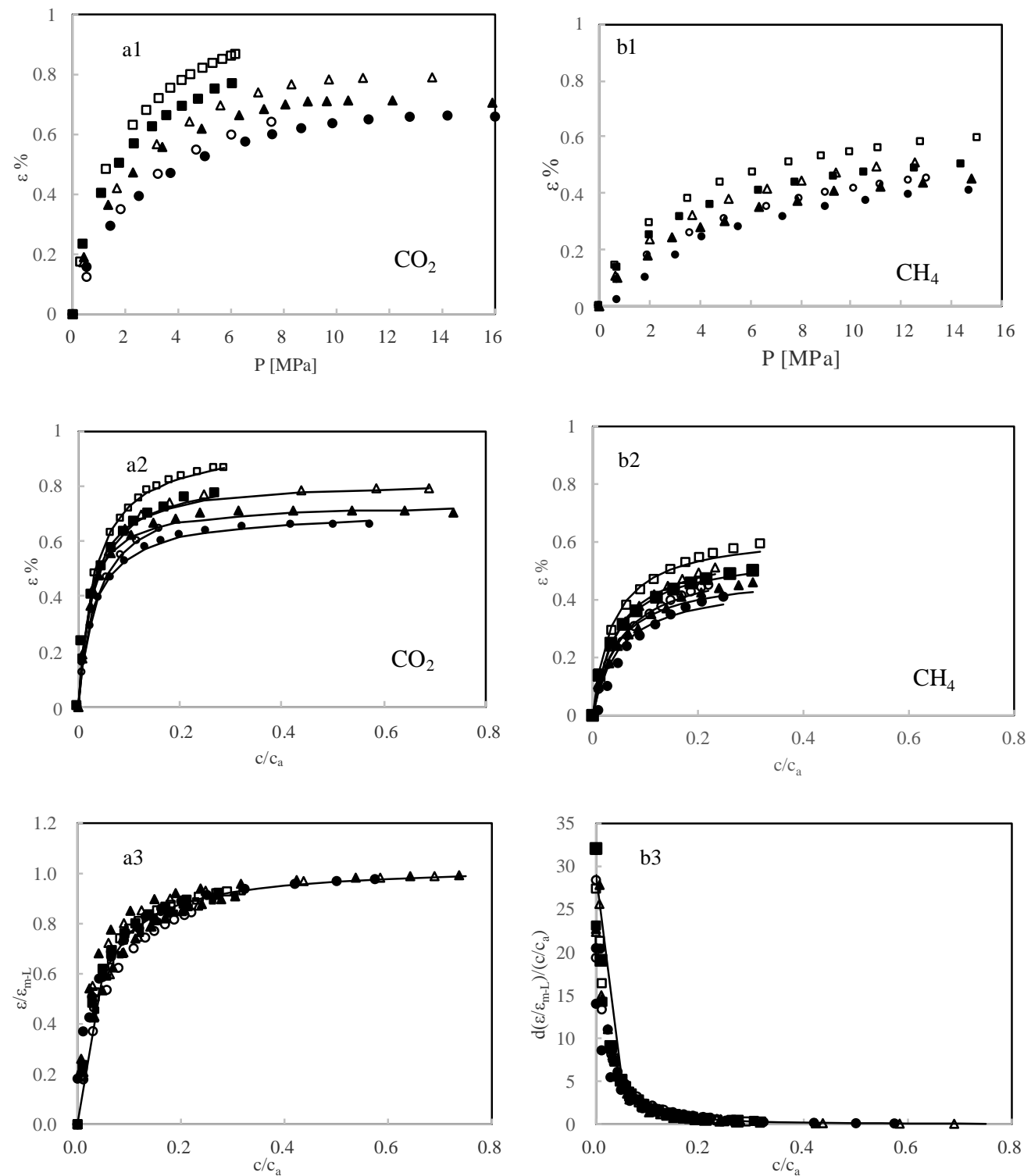

Fig. 3 Swelling isotherms of block coal samples and modeling. a1 and b1: swelling ratio $(\varepsilon)$ vs. equilibrium pressure $(P)$; a2 and b2: swelling ratio $(\varepsilon)$ vs. normalized concentration of bulk phase by that of sorbed phase $\left(c / c_{a}\right)$; a3: normalized swelling ratio by maximum swelling ratio predicted by modified Langmuir model $\left(\varepsilon / \varepsilon_{m-L}\right)$ vs. normalized concentration of bulk phase by that of sorbed phase $\left(c / c_{a}\right)$; b3: rate of change of $\varepsilon / \varepsilon_{m-L}$ with respect to $c / c_{a}$. Filled and unfilled symbols: experimental data of YQ and QS samples; solid lines: fitting results of modified Langmuir model; square, triangle and circle symbols: 25,45 and $65^{\circ} \mathrm{C}$ 

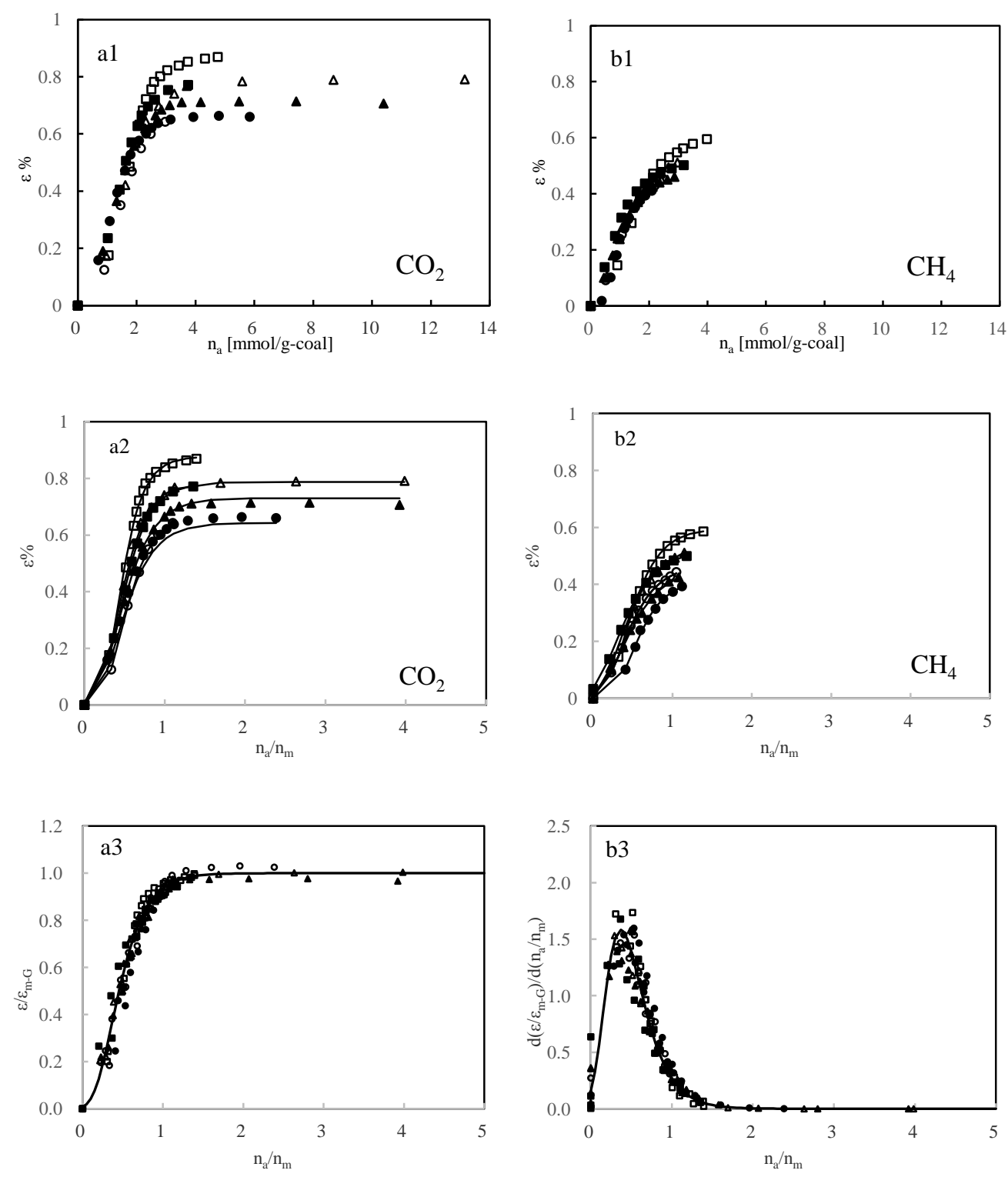

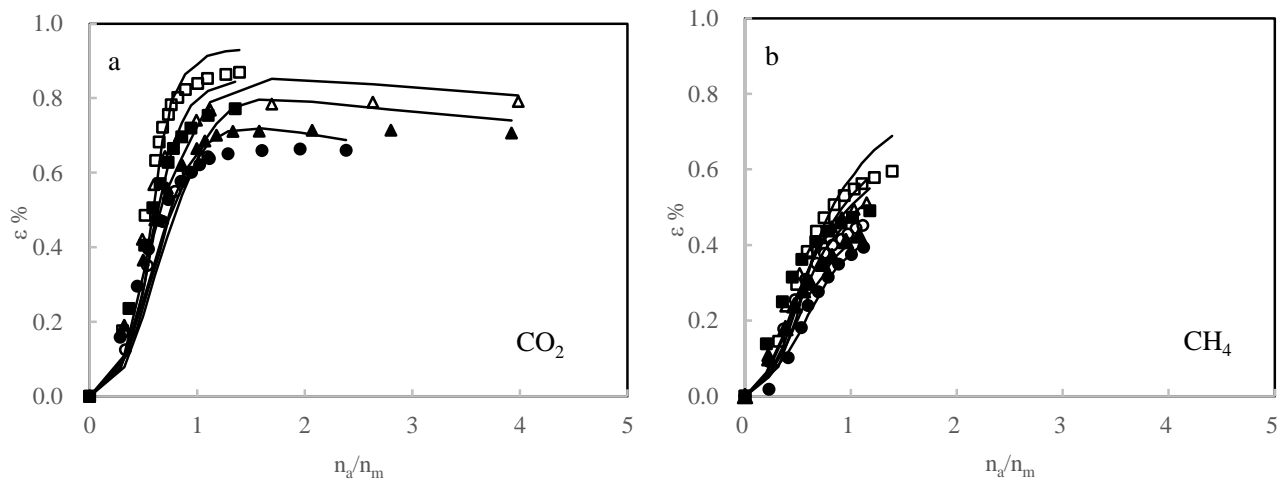

4

5

6

7

8

9

10

11

12

13

14

15

16

17

18

19

20

22

23

24

25

26

27 7 21

Fig.5 Experiment data match of theoretical model with one adjustable parameter. Filled and unfilled symbols: experimental data of YQ and QS samples; solid lines: fitting results.

square, triangle and circle symbols: 25,45 and $65^{\circ} \mathrm{C}$

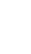

8

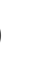

0

1

2

3

\section{5} 6 17 8 9 0 22

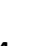
25 6 